\title{
Genetic Disorders of Vision Revealed by a Behavioral Screen of 400 Essential Loci in Zebrafish
}

\author{
Stephan C. F. Neuhauss, ${ }^{1}$ Oliver BiehImaier, ${ }^{3}$ Mathias W. Seeliger, ${ }^{2}$ Tilak Das, ${ }^{4}$ Konrad Kohler, ${ }^{3}$ \\ William A. Harris, ${ }^{4}$ and Herwig Baier ${ }^{5}$ \\ ${ }_{1}^{1}$ Max-Planck-Institut für Entwicklungsbiologie, Abteilung Physikalische Biologie, D-72076 Tübingen, Germany, \\ ${ }^{2}$ Department II and ${ }^{3}$ Experimentelle Ophtalmologie, University Eye Hospital, 72076 Tübingen, Germany, ${ }^{4}$ Department of \\ Anatomy, Cambridge University, Cambridge CB2 3DY, United Kingdom, and ${ }^{5}$ University of California, San Francisco, \\ Department of Physiology, Programs in Neuroscience, Genetics, and Human Genetics, San Francisco, California \\ 94143-0444
}

We examined optokinetic and optomotor responses of 450 zebrafish mutants, which were isolated previously based on defects in organ formation, tissue patterning, pigmentation, axon guidance, or other visible phenotypes. These strains carry single point mutations in $>400$ essential loci. We asked which fraction of the mutants develop blindness or other types of impairments specific to the visual system. Twelve mutants failed to respond in either one or both of our assays. Subsequent histological and electroretinographic analysis revealed unique deficits at various stages of the visual pathway, including lens degeneration (bumper), melanin deficiency (sandy), lack of ganglion cells (lakritz), ipsilateral misrouting of axons (belladonna), optic-nerve disorganization (grumpy and sleepy), inner nuclear layer or outer plexiform layer malfunction (noir, dropje, and possibly steifftier), and disruption of retinotectal impulse activity (macho and blumenkohl). Surprisingly, mutants with abnormally large or small eyes or severe wiring defects frequently exhibit no discernible behavioral deficits. In addition, we identified 13 blind mutants that display outer-retina dystrophy, making this syndrome the single-most common cause of inherited blindness in zebrafish. Our screen showed that a significant fraction ( $~ 5 \%$ ) of the essential loci also participate in visual functions but did not reveal any systematic genetic linkage to particular morphological traits. The mutations uncovered by our behavioral assays provide distinct entry points for the study of visual pathways and set the stage for a genetic dissection of vertebrate vision.

Key words: visual system; vision; retina; tectum; optomotor; optokinetic; albinism; photoreceptor; retinal ganglion cell; outer-retina dystrophy; retinitis pigmentosa; retinal degeneration; mutant screen; mutation; zebrafish; Danio rerio; forward genetics; ERG
The genes that govern the development and function of the vertebrate visual system have been difficult to identify. Functional genetic approaches, which use large-scale mutagenesis screens to isolate mutant phenotypes, offer a powerful way to dissect, at the systems level, biological processes and to subsequently identify the genes involved by mapping and cloning the mutations. Mutant screens were pioneered in Drosophila melanogaster (Benzer, 1973; Nüsslein-Volhard and Wieschaus, 1980) and Caenorhabditis elegans (Brenner, 1974) and have recently been made available for a vertebrate species, the zebrafish (Danio rerio) (Driever et al., 1996; Haffter et al., 1996a). One zebrafish screen used 3000 mutagenized F2 families and was able to isolate 4000 mutations in

Received May 10, 1999; revised July 2, 1999; accepted July 12, 1999.

W.A.H. and T.D. were supported by the Wellcome Trust. O.B. was supported by the Deutsche Forschungsgemeinschaft (GK Neurobiologie). M.W.S was supported by Deutsche Forschungsgemeinschaft Grant SFB 430 C2 and Fortune Grant 517. H.B. was supported by the Humboldt Foundation, the Max Planck Society, and the Department of Physiology at University of California, San Francisco. We thank H.-G. Frohnhöfer (Tübingen stock center) and his team for supply of mutant embryos, C. Nüsslein-Volhard for giving us the opportunity to perform this screen and for providing facility space to H.B., F. Bonhoeffer and E. Zrenner for support; I. Horschke for excellent help with belladonna analysis, C. M. Müller and $\mathrm{H}$. Schwahn for initial help with ERG, and C. Bargmann, D. Copenhagen, A. Kahn, C.-B. Chien, and A. Schier for comments on this manuscript.

Correspondence should be addressed to Stephan Neuhauss, Max-Planck-Institut Entwicklungsbiologie, Spemannstrasse 35/I, D-72076 Tübingen, Germany; or Herwig Baier, University of California, San Francisco, Department of Physiology, 513 Parnassus Avenue, S-762, San Francisco, CA 94143-0444.

Copyright (C) 1999 Society for Neuroscience 0270-6474/99/198603-13\$05.00/0
$>400$ essential genes affecting morphological or anatomical traits (Haffter et al., 1996a). The identified loci were classified according to their involvement in early development, in the formation of body axes, in the development of mesoderm, CNS, internal organs, pigmentation, or jaw and gills, in motility, or in axon guidance. In this paper, we have now reexamined these mutants for defects in visually guided behavior.

Behavioral screens have been conducted before on zebrafish, although not at an exhaustive scale. The prospect of being able to study behavior and CNS function seemed to have motivated G. Streisinger to start his pioneering work in zebrafish genetics (Clark, 1981; Streisinger et al., 1981). In another pioneering work, Brockerhoff et al. (1995) used the optokinetic response to a moving black-and-white grating to screen for mutants in 266 mutagenized F2 families and were able to isolate mutations, one of which causes selective degeneration of the long-wavelength cones (Brockerhoff et al., 1997). Using a different behavioral paradigm, the escape from an approaching object, the same group isolated $n b a$, a dominant mutant with adult retinal degeneration (Li and Dowling, 1997). These studies demonstrate that it is possible to use behavioral assays to identify single-gene mutations in zebrafish that affect visual function.

The Tübingen stock center collection of 450 mutants originally discovered in the large-scale screen represents a library of phenotypes caused by single-gene mutations. The vast majority of these mutations are likely to cause loss-of-function phenotypes. 
Most of them have not been analyzed for behavior other than locomotion and touch responses (Granato et al., 1996). In this study, we asked which fraction of the corresponding genes also contribute to visually guided behaviors. Two complex, CNScontrolled behaviors, the optokinetic response and the optomotor response, were used as screening assays. Two-thirds of all homozygous mutants $(\sim 300)$ could be meaningfully tested for visual behavior. (The rest were early-lethal or paralyzed.) Twelve mutants showed specific and unique disruptions at various levels of the visual system, such as the lens, the photoreceptors, the outer plexiform and inner nuclear layers, the retinal ganglion cells, or the optic tectum, as revealed by physiological and histological analysis. The fraction of essential genes (leading to visible phenotypes when mutated) involved in the emergence and execution of visual behaviors in vertebrates can therefore be estimated to be $\sim 5 \%$.

\section{MATERIALS AND METHODS}

Fish maintenance and breeding. Fish were raised and crossed as previously described (Mullins et al., 1994). Outcrossed sibling pairs were set up to identify heterozygous carriers. Clutches of these identification crosses were used to assess visual behavior as well as crosses of already identified carriers. Embryos were raised at $28^{\circ} \mathrm{C}$ in $\mathrm{E} 3$ medium $(5 \mathrm{~mm} \mathrm{NaCl}, 0.17$ mM KCl, $0.33 \mathrm{~mm} \mathrm{CaCl}_{2}$, and $0.33 \mathrm{~mm} \mathrm{MgSO}_{4}$ ) (Haffter et al., 1996a).

Loci and alleles in alphabetical order. The following loci are mentioned in the text; the alleles tested in our screen are given in parentheses: acerebellar $\left(\right.$ ace $\left.^{\mathrm{ti2} 28 \mathrm{a}}\right)$, albino $\left(\mathrm{alb}^{\mathrm{t} \mathrm{r} 282}\right)$, astray (ast $\left.{ }^{\mathrm{ti} 272 \mathrm{z}, \mathrm{te} 284, \mathrm{te} 378, \mathrm{t} 1231}\right)$, babyface ( $\left(\mathrm{bab}^{\mathrm{tb} 210 \mathrm{c}}\right)$, bajan (baj $\left.{ }^{\mathrm{t} 247 \mathrm{c}}\right)$, bashful (bal ${ }^{\mathrm{tc} 245}$, tp 82 ), belladonna $\left(\right.$ bel $\left.^{\text {tv } 42 \mathrm{z}}\right)$, blanched $\left(\mathrm{bch}^{\mathrm{t} i 282 \mathrm{~b}}\right)$, blasen (bla $\left.{ }^{\mathrm{ta} 90 \mathrm{a}}\right)$, blass (bls $\left.{ }^{\mathrm{tg} 306}\right)$, bleached $\left(\right.$ blc $\left.^{\text {th204b }}\right)$, blowout (blw $\left.{ }^{\text {tc294z }}\right)$, blumenkohl (blu $\left.{ }^{\text {tc257z }}\right)$, blurred $\left(\mathrm{blr}^{\text {tx3 }}\right)$, boxer (box $\left.{ }^{\mathrm{tm} 70} \mathrm{gm}, \mathrm{tm}^{317 \mathrm{c}}\right)$, bumper (bum $\left.{ }^{\mathrm{tg} 413}\right)$, chameleon $\left(\mathrm{con}^{\mathrm{tm} 15 \mathrm{~d}}\right)$, crocodile ( cro $\left.^{\text {tw212d }}\right)$, cyclops (cyc $\left.{ }^{\text {te262c }}\right)$, dackel ( $\left.\mathrm{dak}^{\text {tw25e, to79c }}\right)$, detour $\left(\mathrm{dtr}^{\mathrm{ts} 269}\right.$, te370, $\left.\mathrm{tm}^{\mathrm{m} 276 \mathrm{~b}}\right)$, dropje ( $\left.\operatorname{drp}^{\mathrm{tr} 256}\right)$, fade out $\left(\mathrm{fad}^{\mathrm{tm} 63 \mathrm{c}}\right)$, fading vision $\left(\mathrm{fdv}^{\text {th236a }}\right)$, fata morgana (fam $\left.{ }^{\text {te } 267}\right)$, flathead $\left(\mathrm{fla}^{\mathrm{ta} 53 \mathrm{c}}\right)$, frozen $\left(\right.$ fro $\left.^{\text {to27c }}\right)$, fullbrain (ful $\left.{ }^{\mathrm{tq} 279}\right)$, gnarled (gna $\left.{ }^{\mathrm{tc} 236 \mathrm{z}}\right)$, golden (gol $\left.{ }^{\mathrm{ty} 213 \mathrm{~b}}, \mathrm{b1}, 14 \mathrm{Mdel}\right)$, grumpy (gup ${ }^{\text {tx221a, }}$ tg210a $)$, iguana (igu ${ }^{\text {tm74a }}$ ), ivory (ivy $\left.{ }^{\text {tm271a }}\right)$, lakritz $\left(\mathrm{lak}^{\mathrm{th} 241}\right)$, macho (mao $\left.{ }^{\mathrm{tt} 261 \mathrm{a}}\right)$, masterblind $\left(\mathrm{mbl}^{\mathrm{tm} 13}\right)$, microps $\left(\mathrm{mic}^{\mathrm{tm} 329}\right)$, mirage $\left(\mathrm{mir}_{\mathrm{tm} 15}^{\mathrm{tm} 79 \mathrm{~d}}\right)$, miro (mio $\left.{ }^{\mathrm{tm} 88 \mathrm{z}}\right)$, monorail $\left(\mathrm{mol}^{\mathrm{tv} 53 \mathrm{a}}\right)$, mustard $\left(\mathrm{mrd}^{\mathrm{tn} 215,}{ }^{\mathrm{t} 441}\right)$, nevermind $\left(\mathrm{nev}^{\mathrm{tr} 230 \mathrm{~b},}{ }^{\mathrm{ta} 229 \mathrm{f}}\right)$, noir $\left(\mathrm{nir}^{\mathrm{tp} 89 \mathrm{a}}\right)$, no isthmus $\left(\right.$ noi $\left.^{\mathrm{t} 21,}{ }^{\mathrm{tu} 29 \mathrm{a}}\right)$, one-eyed pinhead (oep $\left.{ }^{\mathrm{tz257a}}\right)$, otter ( $\left.\mathrm{ott}^{\mathrm{ta} 76 \mathrm{~b}}\right)$, pinscher ( $\left.\mathrm{pic}^{\mathrm{to} 216 \mathrm{z},} 14 \mathrm{Mx}\right)$, pirueta ( $\left.\mathrm{pir}^{\mathrm{t} \mathrm{t} 213 \mathrm{~b}}\right)$, puzzle $\left(\mathrm{puz}^{\mathrm{t}}{ }^{\mathrm{p} 49 \mathrm{c}}\right)$, quasimodo

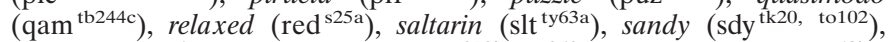

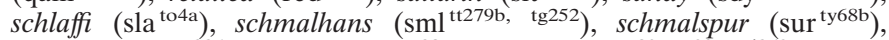
schnitter ( $\left.\mathrm{snt}^{\mathrm{tq} 226 \mathrm{c}}\right)$, sense $\left(\mathrm{sen}^{\mathrm{tm} 28 \mathrm{a}}\right)$, sleepy $\left(\mathrm{sly}^{\mathrm{tm} 89}\right.$, ts33a, ti263a), sloth $\left(\mathrm{slo}^{\mathrm{tu} 244 \mathrm{c}}\right)$, sofa potato $\left(\mathrm{sof}^{\mathrm{ts} 29 \mathrm{a}}\right)$, sonic you $\left(\mathrm{syu}^{\mathrm{tq} 252 \text {, t4deletion }}\right)$, steifftier $\left(\mathrm{ste}^{\mathrm{t}} \mathrm{f}^{220}\right)$, submarine $\left(\mathrm{sum}^{\mathrm{tr} 6}\right)$, sunbleached $\left(\mathrm{sbl}^{\mathrm{to} 4 \mathrm{a}}\right)$, techno-trousers $\left(\mathrm{tnt}^{\mathrm{tk} 57 \mathrm{a}}\right)$, tp 49d $\left(\mathrm{NN}^{\mathrm{tp} 49 \mathrm{~d}}\right)$, twitch-twice ( $\left.\mathrm{twi} \mathrm{i}^{\mathrm{tw} 204 \mathrm{a}}\right), t z 288 b\left(\mathrm{NN}^{\mathrm{tz} 288}\right)$, $u$-boot (ubo $\left.{ }^{\text {tp39c }}\right)$, umleitung (uml ${ }^{\text {ty54z }}$ ), viper (vip ta52e, tb212e), wavy (way ${ }^{\text {ta51x }}$ ), who cares (woe $\left.{ }^{\text {tr221z }}\right)$, you-too $\left(\right.$ yot $\left.^{\text {ty119a }}\right)$, ziehharmonika $\left(\mathrm{zim}^{\mathrm{tt} 22 \mathrm{a}}\right)$. Information about test results for other mutants are available from the corresponding authors upon request.

Optokinetic assay. Figure 1 illustrates the optokinetic assay. Tests similar to those of Brockerhoff et al. (1995) and Easter and Nicola (1996) were performed. Up to 20 larvae [5-8 d postfertilization (dpf)] were transferred into a Petri dish (diameter $3.5 \mathrm{~cm}$ ), containing $2.5 \%$ methylcellulose $\left(28^{\circ} \mathrm{C}\right)$ in E3 medium to partially immobilize the larvae. Immobilization helps suppress the optomotor response (OMR) and permits easy scoring of eye movements. To allow optimal viewing conditions, larvae are positioned dorsal-up with the help of a dissecting needle. The dish is placed inside a rotating drum (diameter, $5 \mathrm{~cm}$ ) fitted with black and white stripes (eight black stripes of $23^{\circ}$ width). The drum was illuminated by white light from above and rotated at $4-12 \% \mathrm{sec}$. Optokinetic responses (OKRs) were elicited by clockwise and counterclockwise rotation. At least five homozygous mutants were analyzed in at least two separate experiments.

Optomotor assay. Figure 2 shows the optomotor screening rig. Up to 100 larvae from one clutch are transferred into one of the 10 chambers. Ten clutches can be tested in parallel. It is not necessary to sort mutants from wild-type siblings before testing, because $25 \%$ abnormal fish can be easily scored. Zebrafish do not school at this age. The stimulus movie consists of 20 frames of a $60^{\circ}$ sine wave grating drifting across the monitor at $4 \mathrm{~Hz}$. Movies were generated using NIH Image for the Macintosh and are available from H.B. on request. Wild-type fish swim with the perceived motion and accumulate at one end of the chamber within $1 \mathrm{~min}$ after onset of the motion stimulus. A failure to respond within 5 min was set as the criterion for optomotor blindness. The whole assay procedure, including transfer, testing, and note keeping, takes $\sim 5$ min for 10 clutches.

Electroretinogram recordings. To localize defects in the visual pathway of mutants, electroretinograms (ERGs) of larval retinae were recorded (Seeliger et al., 1998). The ERG measures light-evoked sum potentials at the corneal surface of the retina. In wild type, the most prominent components of the ERG are the short, negative a-wave followed by the extended, positive b-wave. The a-wave originates from photoreceptor activity. The b-wave is attributed largely to the transretinal current flow in the radially oriented Müller glia cells, as they are depolarized by extracellular potassium, and is thought to reflect the activity of bipolar neurons (for review, see Dowling, 1987). A typical recording from a $5 \mathrm{dpf}$ wild-type retina is shown in Figure $3 A$.

Dark-adapted $(>2 \mathrm{hr}$ ) larvae were anesthesized and paralyzed in $0.02 \%$ buffered 3-aminobenzoic acid methyl ester (Sigma, St. Louis, MO) and $0.8 \mathrm{mg} / \mathrm{ml}$ Esmeron (Organon Teknika, Eppelheim, Germany). In dim red light, sedated larvae were placed on a wet paper towel sitting on a platinum wire, which served as the reference electrode. A glass microelectrode ( $\sim 20 \mu \mathrm{m}$ tip opening) was placed on the center of the cornea by means of a micromanipulator (M330R; World Precision Instruments, Sarasota, FL). The microelectrode holder was directly connected to a voltage follower (VF2; World Precision Instruments), which in turn was interfaced with an input channel of the ERG amplifier. The whole setup was placed inside a Ganzfeld bowl of a commercially available ERG setup (Toennies Multiliner Vision; Jaeger/Toennies, Höchberg, Germany). The scotopic protocol for the analysis of retinal function (Seeliger et al., 1998) was developed on the basis of the human ERG standard by the International Society for Clinical Electrophysiology of Vision (Marmor and Zrenner, 1995). Sessions included single flash recordings at light intensities increasing from 0.1 to $2.5 \mathrm{mcd} / \mathrm{m}^{2}$. Ten responses per intensity were averaged, with an interstimulus interval of $5 \sec (0.1,1,4,10,40$, and $\left.100 \mathrm{mcd} / \mathrm{m}^{2}\right)$ or $17 \mathrm{sec}\left(1\right.$ and $\left.2.5 \mathrm{~cd} / \mathrm{m}^{2}\right)$. In some cases, a bright flash of $10 \mathrm{~cd} / \mathrm{m}^{2}$ was used.

Histology and axon tracing. For Richardson staining, larvae were fixed in $4 \%$ paraformaldehyde, dehydrated through a series of ethanol washes, and embedded in Technovit 7100 (Heraeus Kulzer, Wehrheim, Germany). After polymerization at room temperature the specimens were sectioned at $2 \mu \mathrm{m}$, collected onto slides, stained with aqueous $1 \%$ methylene blue-1\% azure solution, and examined under the light microscope. The retinotectal projection was assessed by injecting the lipophilic tracer DiI into the eye of aldehyde-fixed larvae using the injection apparatus and protocol described by Baier et al. (1996) or by whole-eye fills of DiI (1\% in chloroform) using the same apparatus.

\section{RESULTS}

\section{Optokinetic and optomotor responses can be used to screen for visual mutants}

We first asked whether our behavioral assays could be used to screen for mutants. It was found that both the test for OKRs and the test for OMRs reliably detect visual impairments in zebrafish larvae.

An OKR is elicited by slowly moving an image across the retina. This stimulation can be accomplished by horizontally rotating a drum with black stripes around the larva (Brockerhoff et al., 1995; Easter and Nicola, 1996) (Fig. 1A). The OKR consists of two separate but linked eye movements: first, a smooth pursuit movement in the direction of the rotation; and second, a fast reset movement after the image leaves the visual scanning field (Fig. $1 B)$. At $5 \mathrm{dpf}$, i.e., $2 \mathrm{~d}$ after hatching, $100 \%$ of wild-type fish consistently display the behavior.

To evoke the OMR, the screen of a computer monitor is positioned just below the experimental chamber (Fig. 2A). Apparent motion is generated by cycling four digital image frames, displaying a set of alternating vertical bars, which are displaced by half a bar width from frame to frame (Fig. $2 B$ ). The same result 


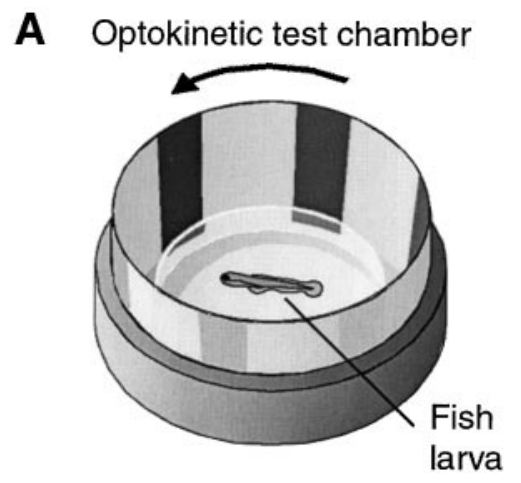

B Wild-type optokinetic response

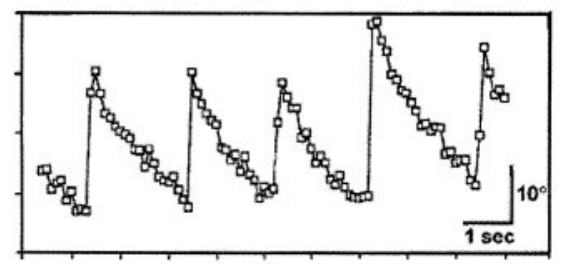

Figure 1. Optokinetic assay. A, Larvae are placed in a Petri dish (containing methylcellulose) inside a rotating drum fitted with black and white stripes. The actual size of larva is proportionally much smaller than depicted in the diagram. $B$, Periodic stimulation leads to periodic optokinetic responses. The angle of eye gaze, when plotted as a funtion of time, has a sawtooth shape. The slow ramp indicates the pursuit movement, and the fast reset indicates the saccade back to the initial position. Eye movements were observed through a dissecting scope and analyzed off-line from a video recording.

is obtained by using 20 frames of a sine wave grating to create smoother motion, which imposes less strain on the eyes. Ten elongated acrylic chambers are placed on top of the screen (Fig. $2 C$ ), each containing a water-filled channel. The channels are oriented at right angles to the moving stripes. Twenty to 100 larvae are placed into the chamber, where they can see the drifting grating through the bottom of the chamber. Wild-type fish follow the motion and accumulate at one end of the channel (Fig. 2D), whereas blind mutants swim in random directions. In a healthy wild-type clutch, $\sim 90 \%$ of fish respond to an optomotorinducing stimulus within $60 \mathrm{sec}$; nearly $100 \%$ respond over $4 \mathrm{~min}$.

\section{Of 411 mutant loci, two-thirds can be scored for behavior, and $\mathbf{2 5}$ are visually impaired}

We asked what fraction of the essential genes previously discovered contribute to the development or execution of visual behaviors. It could be that visual behavior is controlled by genetic pathways that overlap primarily with those used in the development of other tissues. In this case, we would expect to find a large percentage of visual mutants in the collection available to us. Alternatively, the visual system could be established by a separate set of genes, in which case we would not be able to detect any specific visual system phenotypes among the available mutants. Below we show that a small but significant fraction of essential genes also have visual system phenotypes. The statistics of our screen are summarized in Table 1.

During our screen, before any behavioral tests, we scored the phenotypes of 450 mutations of 411 essential genes based on published morphological criteria (Haffter et al., 1996a). For 35 genes more than one allele were available. Early-embryonic lethal or completely paralyzed mutants were excluded from the behav-
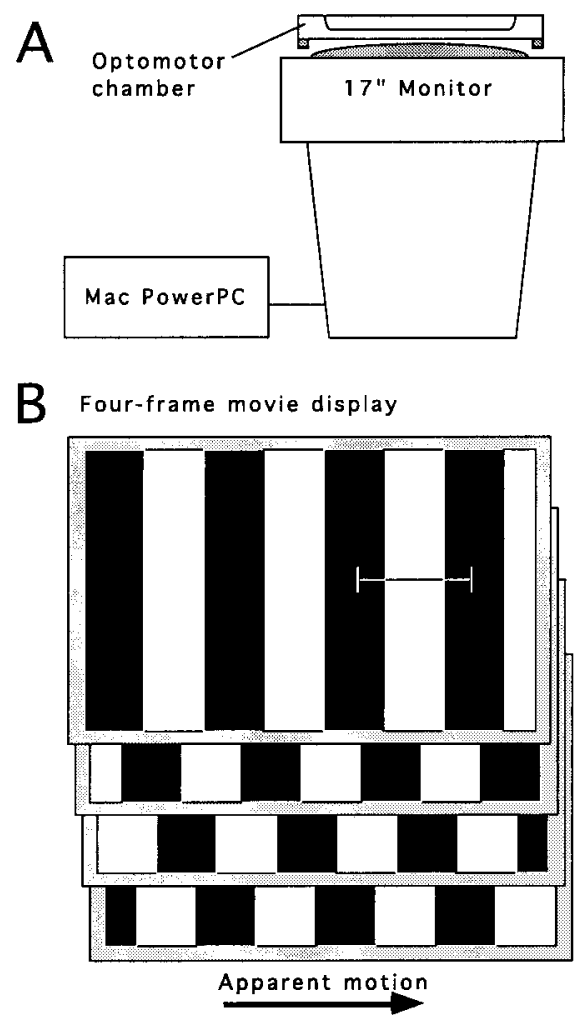

C Transparent optomotor chamber

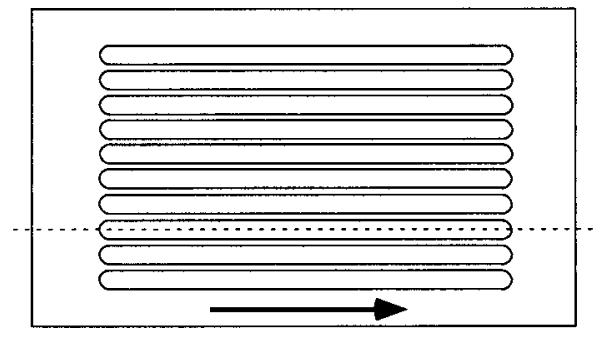

Cross section (at position indicated above)

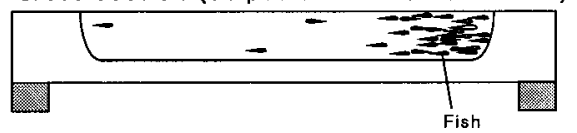

$D$ Distribution of fish larvae

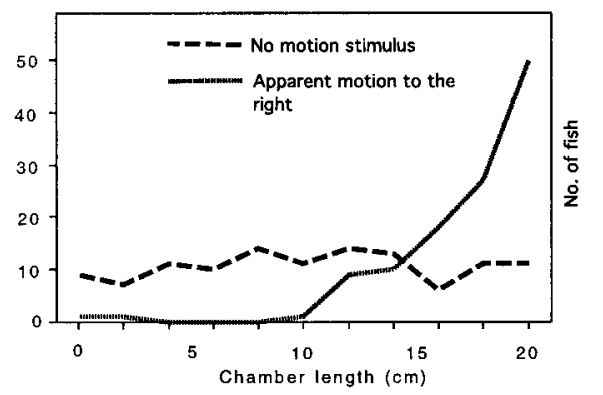

Figure 2. Optomotor assay. A, Motion stimuli are generated by a computer and displayed by a computer monitor, which has been flipped on its back. $B$, Repetitive cycling of four digital movie frames showing a periodic luminance-modulated grating gives apparent motion. The grating seems to drift across the monitor. $C$, Elongated, transparent chambers with U-shaped cross-sections can hold up to 100 fish larvae for optomotor tests. Ten chambers are used in parallel. Fish can see the grating through the bottom of the channels. $D$, Wild-type fish respond to the motion by optomotor behavior and accumulate at one end of the chamber. 
$\overline{\text { Table 1. Behavioral rescreen of } 450 \text { zebrafish mutants for visual defects }}$

\begin{tabular}{lll} 
& $\begin{array}{l}\text { Optokinetic } \\
\text { assay }\end{array}$ & $\begin{array}{l}\text { Optomotor } \\
\text { assay }\end{array}$ \\
\hline Total number of loci in the screen & 340 & 411 \\
Total number of mutant alleles in the screen & 360 & 450 \\
Testable recessive phenotypes & 266 & 197 \\
Dominant mutants & Not tested & 0 \\
Nonspecific mutants (brain, locomotion) & 40 & 38 \\
Specific mutants (visual pathway) & 24 & 17 \\
\hline
\end{tabular}
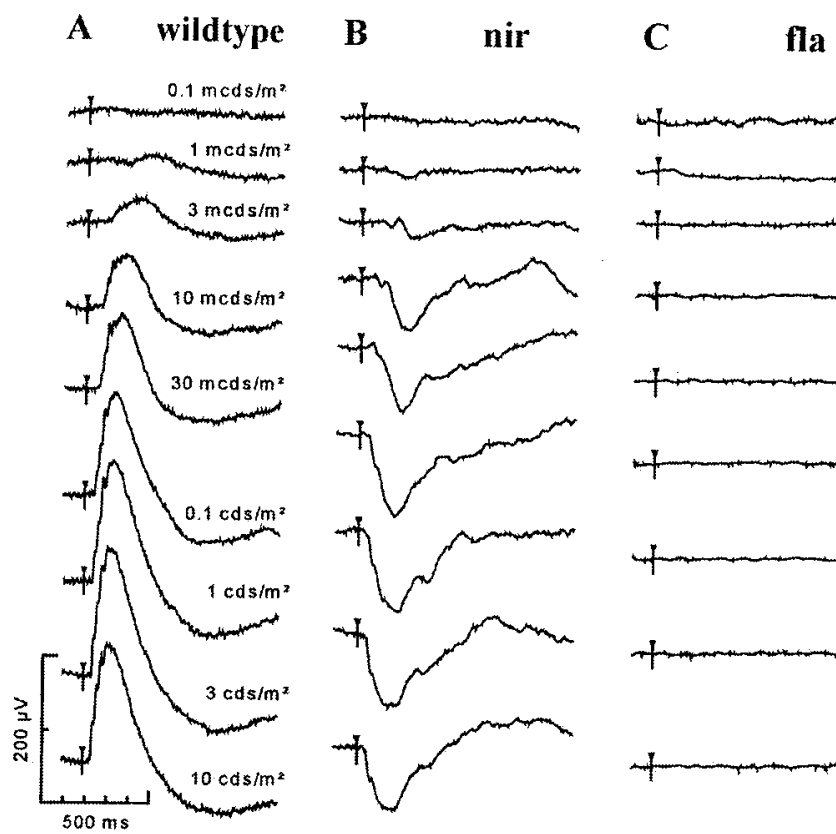

Figure 3. ERGs of wild-type visual responses and two examples of mutant responses. ERGs were recorded from 5-d-old dark-adapted larvae at flash intensities from $0.1 \mathrm{mcd} / \mathrm{m}^{2}$ to $10 \mathrm{~cd} / \mathrm{m}^{2}$. Up to 10 responses per intensity were averaged. $A$, Wild-type larvae show a typical vertebrate ERG composed of a-wave and b-wave (see text). B, noir (nir) mutants lack a b-wave response but still exhibit an a-wave (photoreceptor response) indicating inner nuclear layer dysfunction. $C$, flathead ( $\mathrm{fla}$ ) mutants lack any response to light. The two mutants in $B$ and $C$ are behaviorally blind. Open triangles indicate onset of stimulus.

ioral tests, but the OMR of their heterozygous siblings was assessed to reveal any dominant or haploinsufficient phenotypes. In the OKR screen, 261 loci and, in the OMR screen, 197 loci could be tested in the homozygous condition (Table 1). Among the homozygous mutants, our behavioral assays uncovered more than 65 mutants that failed one or both of our tests. More detailed behavioral analysis, electroretinography (for a wild-type ERG, see Fig. $3 A$ ), and histology (for a wild-type retina, see Fig. 4A) were used to find out whether the mutations induced specific disruptions of the visual pathway. More than 40 mutants turned out to show nonspecific behavioral phenotypes attributable to locomotor defects, brain degeneration, or abnormal brain development. For completeness, we have summarized many of them in Table 2. This group is not considered further here. No dominant or haploinsufficient behavioral phenotypes could be detected.

In 25 mutants, the defect could be localized specifically to the visual system and, with ERG and histology, to layers or cell types within the retina or to the retinotectal projection. Thirteen mu-
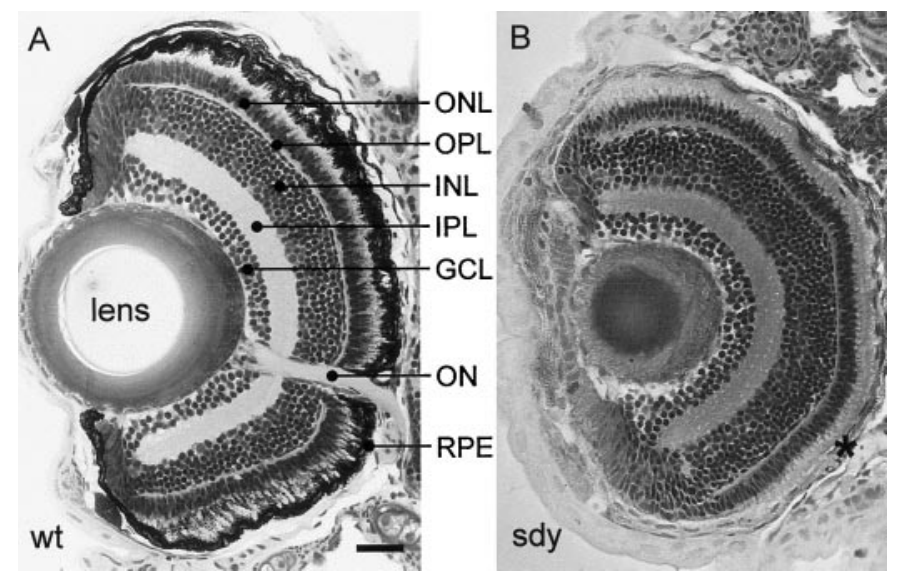

Figure 4. Retinal histology of 5-d-old wild-type and sandy mutant zebrafish. $A$, Transverse plastic section of a wild-type retina. $B$, The sandy retina reveals a melanin-deficient RPE (asterisk) but an otherwise normal layering of the retina. This mutant is behaviorally blind but shows a normal ERG (data not shown). IPL, Inner plexiform layer; $O N$, optic nerve; $O N L$, outer nuclear layer; $O P L$, outer plexiform layer. Scale bar, $50 \mu \mathrm{m}$.

tants (of the 25 in the final group) share in common the trait that their retina degenerates in late embryonic or early larval stages (Table 3). The remaining 12 mutants show unique phenotypes, defective at different stages along the visual pathway (Table 4). The corresponding genes, which we regard as being specifically involved in visual function and development, are bumper, sandy, sleepy, grumpy, pinscher, lakritz, belladonna, noir, dropje, steifftier, macho, and blumenkohl. Our numbers allow us to estimate that $5 \%$ (or fewer) essential genes (mutation of which lead to a visible phenotype) also participate in the establishment of visual functions, and another $5 \%$ prevent degeneration of photoreceptors.

\section{Blind zebrafish fail to adapt to the background}

Zebrafish larvae, like other teleosts, adjust the distribution of melanin pigment in their skin to ambient light levels. When placed on a dark background, melanin granules (also called melanosomes) become widely distributed within the processes of star-shaped black pigment cells, the melanophores. As a result, when viewed from a distance, the animal appears blackish. When placed on a light background, melanosomes become aggregated, and the animal appears pale. A direct projection from the retina to the hypothalamus provides the sensory input to this adaptation response. In most teleosts, the hypothalamus then induces the pituitary to secrete two hormones with antagonistic actions on the melanophores, one for dispersal and the other for aggregation of melanin (for review, see Balm and Groeneveld, 1998). More than 20 mutants with dispersed melanin ("expanded melanophores") were reported in the original screen (Haffter et al., 1996; Kelsh et al., 1996). No attempts had been made to locate the underlying deficits, except for the mutant bumper, which shows progressive lens degeneration at variable penetrance (Heisenberg et al., 1996). We confirmed with our behavioral assays that bumper mutants are visually impaired to varying degrees. Their individual visual impairments in the OMR correlate with the failure of melanin aggregation after adaptation to a bright background. The darker the fish, the more defective its vision, and vice versa.

Thirteen mutants in our collection that fail to adapt to the background are also clearly blind (Tables 3, 4). Other mutants with apparent failure to aggregate pigment display normal OKR 


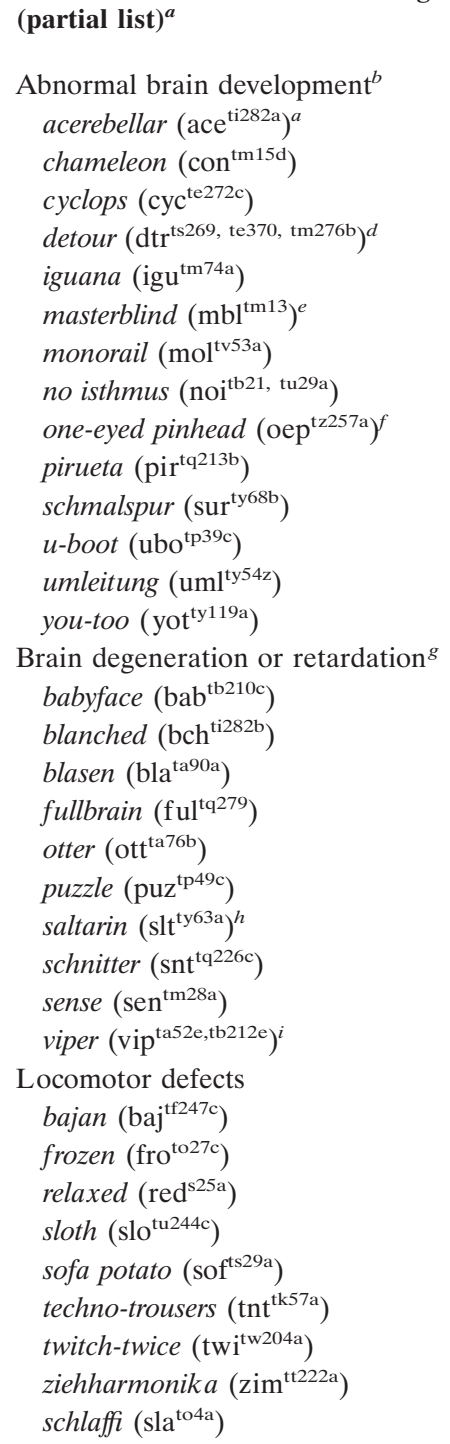

${ }^{a}$ The criteria for including a given mutant in this list must be somewhat arbitrary. Severely abnormal mutants have generally been omitted. So have mutants that have not been tested for complementation. Only the alleles tested in this study are given in parentheses. For a complete list of alleles, see Haffter et al. (1996a).

${ }^{b}$ These phenotypes are frequently associated with defects in midline signaling. Note that the midline-signaling mutants sonic you (syu ${ }^{\text {tq252, }}$ t 4 deletion $)$, and schmalhans $\left(\mathrm{sml}^{\mathrm{tt} 279 \mathrm{~b}, \mathrm{tg} 252}\right)$ show appropriate visual responses.

${ }^{c}$ Five percent of acerebellar mutants show OKR.

${ }^{d}$ Most detour mutants show no response; some show residual responses to movement; very few show reversed OKR.

${ }^{e}$ masterblind mutants have severely reduced eyes.

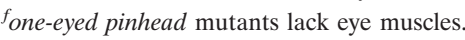

${ }^{g}$ In addition to the loci listed, we found $>15$ mutants with brain degeneration to be also defective in behavior. This group was not kept systematically in the large-scale screen (Furutani-Seiki et al., 1996) and has not been resolved in complementation groups.

${ }^{h}$ Brain degeneration in saltarin has not been reported previously.

iviper mutants occasionally show an OKR.

and OMR, most prominently fata morgana, submarine, microps, and wavy. We hypothesize that the latter mutants are defective in melanophore-autonomous functions, or in the neuroendocrine signals that mediate the response. Conversely, two of the visually irresponsive mutants, sleepy and grumpy (see below, Table 4), show proper background adaptation. In conclusion, behavioral blindness correlates with but cannot be safely predicted from lack of background adaptation.

\section{Blindness is linked to melanin deficiency in sandy albinism}

sandy mutants do not form melanin pigment, neither in the body nor in the eye, and are visually defective, as seen in their failure to perform the OKR or OMR. At larval stages, the phenotype is very strong with no visual response detectable at all. Adult sandy mutants can be startled by a large moving object and tend to stay in the darkest area of their tank (H. Baier, unpublished observation). The larval retina appears normal as judged by histology (Fig. 4B), except for the complete absence of melanin in the retinal pigment epithelium (RPE). The cells that constitute the $\mathrm{RPE}$ are morphologically normal. The cause of visual dysf unction in sandy is not fully understood.

We first asked whether albinism was generally associated with visual problems in zebrafish. Previous screens had uncovered four different zebrafish loci involved in the formation of melanin, in addition to sandy. Mutations in these genes, golden, albino, brass, and mustard, lead to albinism of variable expressivity up to adult stages. Although we did not attempt to determine their threshold sensitivities, these mutants appear all normal in their OKR and OMR. sandy, therefore, is unique among the albinistic loci in the severity of its effect on the visual system.

The RPE is assumed to play an important role in protecting the photoreceptors from light-induced damage. A straightforward explanation for the deterioration of vision in sandy could be the extensive bleaching of visual pigments. We can exclude this possibility from our physiological measurements. The sandy retina shows a normal (or sometimes even supernormal) ERG, which indicates that photoreceptors are functionally intact. Also, we could not detect photoreceptor damage at the lightmicroscopic level.

Another function of the RPE is to absorb stray light, which otherwise would degrade the quality of the retinal image. At larval stages, when the fish is $<1 \mathrm{~mm}$ wide and translucent, particularly in the absence of melanin pigment, light could indeed enter the retina from all directions and blur the image. We addressed this hypothesis by testing sandy mutants in the optomotor assay under low-light conditions using dark gray stripes on a black background, thus reducing the absolute amount of stray light. Light could enter the chamber only from below. At a contrast setting at which wild-type fish were just able to see the grating (Michelson contrast, 5\%, calculated from photometer readings taken directly from the computer screen), sandy mutants did not respond $(n=16)$. We also varied stripe width and velocity of the grating to account for possible degradation of spatial or temporal resolution but never observed a response. (The coarsest grating we used was composed of stripes that covered $90^{\circ}$ of visual angle; the wild-type acuity was previously determined to be $8^{\circ}$; Clark, 1981). Although the amount of light scatter is hard to measure accurately, it seems unlikely that this effect degrades the image to an extent that could completely abolish pattern vision in sandy.

In the sandy retina shown in Figure $4 B$, the lens appears somewhat shrunk and opaque. Although this is not a consistent feature of the sandy phenotype and is occasionally observed in sections of wild type, too, (because of slow fixation), we followed up on the possibility of a lens defect, which could cause hyperopic or myopic blur. We first tested whether the freshly dissected sandy lens was any different in size or optical appearance from wild- 


\begin{tabular}{|c|c|c|c|c|}
\hline Gene & Allele & $\begin{array}{l}\text { PhR defect } \\
\text { (visible at } 6 \mathrm{dpf} \text { ) }\end{array}$ & $\begin{array}{l}\text { RPE defect } \\
\text { (visible at } 6 \mathrm{dpf} \text { ) }\end{array}$ & Other cell types or tissues affected ${ }^{a}$ \\
\hline blass & bls ${ }^{\operatorname{tg} 306 a}$ & No & Yes & Melanophores ( 8 , renamed in this paper) \\
\hline bleached & blc $\mathrm{c}^{\mathrm{th} 204 \mathrm{~b}}$ & No & Yes & Melanophores, ear, CNS $(3,6,8,14)$ \\
\hline blurred & $\mathrm{blr} \mathrm{r}^{\mathrm{t} \times 3 \mathrm{c}}$ & No & Yes & Melanophores $(6,8)$ \\
\hline fade out & $\mathrm{fad}^{\mathrm{tm} 63 \mathrm{c}}$ & Yes & Yes & Melanophores $(6,8)$ \\
\hline fading vision & $f d v^{\text {th236a }}$ & Yes & Yes & Melanophores, CNS $(3,5,8)$ \\
\hline mirage & $\operatorname{mir}^{\mathrm{tm} 79 \mathrm{~d}}$ & No & Yes & Melanophores $(6,8)$ \\
\hline ivory & $\operatorname{Ivy}^{\mathrm{tm} 271 \mathrm{a}}$ & Yes & Yes & Melanophores, CNS $(3,6,8)$ \\
\hline quasimodo & $\mathrm{qam}^{\mathrm{tb} 244 \mathrm{c}}$ & No & Yes & Melanophores, notochord $(8,9)$ \\
\hline sunbleached & $\mathrm{sbl}^{\mathrm{to} 4 \mathrm{a}}$ & Yes & Yes & Melanophores, jaw, branchial arches $(6,8,12)$ \\
\hline crocodile & $\mathrm{cro}^{\mathrm{tw} 212 \mathrm{~d}}$ & Yes & No & Other neurons (4) \\
\hline flathead & $\mathrm{fla}^{\mathrm{ta} 53 \mathrm{c}}$ & Yes & No & CNS, jaw and branchial arches $(6,8,12)$ \\
\hline$t p 49 d$ & $\mathrm{NN}^{\mathrm{tp} 49 \mathrm{~d}}$ & Central retina & No & Kidney $(1,2)$ \\
\hline$t z 288 b$ & $\mathrm{NN}^{\mathrm{tz} 288 \mathrm{~b}}$ & Central retina & No & Kidney $(1,2)$ \\
\hline
\end{tabular}

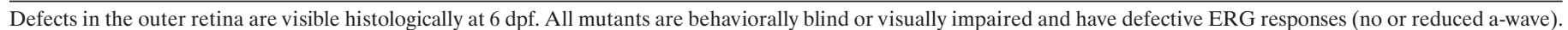

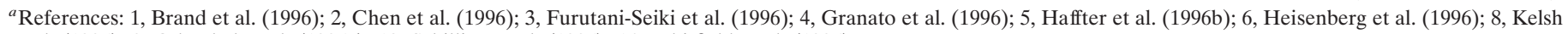
et al. (1996); 9, Odenthal et al. (1996a); 12, Schilling et al. (1996); 14, Whitfield et al. (1996).

type. This was not the case (data not shown). We then measured directly its refractive power in the intact fish, following the procedure given by Easter and Nicola (1996). In short, black lines were drawn on a small transparency sheet, and the sheet was then inserted into the light path of a compound microscope at the level of the condenser lamp. Looking through the eyepieces under Köhler illumination, we could obtain a sharp image of the black lines. We then placed an unfixed sandy larva at $7 \mathrm{dpf}$ on the microscope stage and examined it at $400 \times$ magnification. As described by Easter and Nicola (1996), light that passes through the fish lens is focused onto a plane that is different from that of neighboring light because of refraction by the lens. A normalsighted lens will focus the outline of an object exactly onto the plane of the photoreceptor outer segments. When we focused on the outer retina (where the photoreceptors are situated), we obtained a sharp image of the black lines cast through the fish lens. When we focused on the inner retina or onto a plane outside of the retina, the image of the black lines was blurred. This observation supports the hypothesis that the sandy lens is well able to form an image in the photoreceptor layer and that the sandy eye is neither myopic nor hyperopic.

In mammals, albinism is frequently associated with other visual system abnormalities, such as a deficit of rods (Jeffery et al., 1994), misrouting of ipsilaterally projecting axons (Cooper and Pettigrew, 1979; Rice et al., 1995; Jeffery, 1997), and the absence of a fovea (Elschnig, 1913; Stone et al., 1978). In sandy, retinal histology (Fig. $4 B$ ) and the retinotectal projection (as assessed by DiI tracing) are indistinguishable from wild type. Also, zebrafish do not possess a prominent fovea and have no ipsilateral projection. These abnormalities seem to be specific to mammalian albinos and cannot account for the loss of vision in sandy.

\section{Outer-retina dystrophy is the single most common cause of genetic blindness in zebrafish}

More than half of the specific mutants turned up by our screen, 13 of 25, show deficits in the maintenance of the RPE, the photoreceptors (PhRs), or both (Table 3). As in the human population (Gregory-Evans and Bhattacharya, 1998), outer-retina dystrophy seems to be the most common cause of inherited blindness in mutagenized zebrafish.

In nine mutants that failed both the OKR and the OMR, the
RPE is pale, grayish, or patchy, indicating degeneration (bleached, blurred, fade out, fading vision, ivory, mirage, quasimodo, sunbleached, and blass). A common feature of this group (except for mirage and quasimodo) is that their body melanophores fail to differentiate properly during development and accumulate at abnormal places, such as under the ear, around the eye, and around the hindgut. PhRs adjacent to areas of RPE degeneration undergo cell death in fade out, ivory (Fig. 5A), blurred, sunbleached, and fading vision. In the remaining mutants (bleached, mirage, quasimodo, and blass; Fig. 5B), we did not directly observe dying $\mathrm{PhR}$, but this may be a limitation of our histological method. Whenever tested, the ERG in these mutants is reduced or absent depending on the stage of $\mathrm{PhR}$ degeneration.

Four mutants (crocodile, flathead, tp49d, and $t z 288 b$ ) fail in OKR and OMR (if testable), lack an ERG (Fig. 3C; flathead ERG), and exhibit PhR degeneration without overt signs of RPE degeneration. Homozygous flathead larvae develop RPE hypertrophy (data not shown). Retinas of homozygous crocodile larvae reveal shorter outer segments of the PhR in early stages. Later there is an apparently complete lack of this cell type but no obvious changes in the RPE (data not shown). In both tp $49 d$ and $t z 288 b$ (Fig. 5C), $\mathrm{PhR}$ degeneration begins in the central retina and spreads into the periphery. Because the teleost retina is constantly proliferating at the margin the more pronounced degeneration in central locations might be attributable to the greater age of these cells. Although the latter two mutants share in common other morphological symptoms, such as pronephric cysts, they were found to be nonallelic in a recent complementation test.

\section{Of the retinotectal pathfinding mutants, sleepy, grumpy, and pinscher are visually disturbed}

In a previous screen, 25 loci were identified that affect the projection of the retinal ganglion cell (RGC) to the tectum (Baier et al., 1996; Karlstrom et al., 1996; Trowe et al., 1996). We expected these mutants to be among the best candidates for visual impairments. However, most of them are surprisingly normal in their visual behavior, as far as testable (some do not swim, but nearly all move their eyes). Most strikingly, the mutants gnarled, miro, nevermind, and who cares respond properly to our visual test 
Table 4. Specific visual disorders in zebrafish mutants (ordered according to their likely primary defect)

\begin{tabular}{|c|c|c|c|c|c|c|c|c|}
\hline \multicolumn{2}{|l|}{ Locus } & \multicolumn{3}{|c|}{ Visual behavior } & \multicolumn{4}{|c|}{ Anatomy and physiology } \\
\hline Gene & Allele & OKR & OMR & VBA & Retinal histology & $\begin{array}{l}\text { ERG re- } \\
\text { sponse }\end{array}$ & $\begin{array}{l}\text { Retinotectal projec- } \\
\text { tion }^{a}\end{array}$ & Other phenotypes $^{a}$ \\
\hline \multicolumn{9}{|c|}{ Lens degeneration } \\
\hline bumper & bum $^{\operatorname{tg} 413}$ & Partial & Partial & Partial & $\begin{array}{l}\text { Normal (lens degen- } \\
\text { eration) }\end{array}$ & ND & Normal & None (6) \\
\hline \multicolumn{9}{|l|}{ Albinism } \\
\hline sandy & $\mathrm{sdy}^{\mathrm{tk} 20 \mathrm{a}}$ & Defective & Defective & - & $\begin{array}{l}\text { Normal (RPE mela- } \\
\text { nin-deficient) }\end{array}$ & $\begin{array}{l}\text { (Super)- } \\
\text { Normal }\end{array}$ & Normal & $\begin{array}{l}\text { No melanin in body } \\
\text { and eye (8) }\end{array}$ \\
\hline \multicolumn{9}{|c|}{ Axon growth and pathfinding errors } \\
\hline grumpy & $\operatorname{gup}^{\mathrm{tx221a}}$ & Defective & - & Normal & $\begin{array}{l}\text { GCL and optic } \\
\text { nerve disorga- } \\
\text { nized; lens mal- } \\
\text { formed }\end{array}$ & Normal & $\begin{array}{l}\text { RGC axons disorga- } \\
\text { nized ( } 7)\end{array}$ & $\begin{array}{l}\text { Notochord and } \\
\text { brain defects (9) }\end{array}$ \\
\hline sleepy & $\operatorname{sly}^{\mathrm{ts} 33 \mathrm{a}}$ & Defective & - & Normal & $\begin{array}{l}\text { PhR outer segments } \\
\text { smaller }\end{array}$ & ND & $\begin{array}{l}\text { RGC axons disorga- } \\
\text { nized ( } 7)\end{array}$ & $\begin{array}{l}\text { Notochord and } \\
\text { brain defects (9) }\end{array}$ \\
\hline pinscher & $\mathrm{pic}^{\mathrm{to} 216 \mathrm{z}}$ & Partial & Partial & Defective & $\begin{array}{l}\text { Slightly more INL } \\
\text { cells }\end{array}$ & Normal & $\begin{array}{l}\text { Abnormal branching } \\
\text { of optic tract }(7,13)\end{array}$ & $\begin{array}{l}\text { Jaw and branchial } \\
\text { arches abnormal } \\
(11,13)\end{array}$ \\
\hline \multicolumn{9}{|c|}{ Misrouting to ipsilateral tectum } \\
\hline belladonna & bel $^{\mathrm{tv} 42 \mathrm{z}}$ & Reverse & Normal & Normal & Normal & Normal & $\begin{array}{l}\text { Projection to ipsilat- } \\
\text { eral tectum (7) }\end{array}$ & $\begin{array}{l}\text { Pigment defect } \\
\text { around eye (7) }\end{array}$ \\
\hline \multicolumn{9}{|c|}{ Lack of retinal ganglion cells } \\
\hline lakritz & $\mathrm{lak}^{\mathrm{th} 241 \mathrm{c}}$ & Partial & Defective & Defective & $\begin{array}{l}\text { Thin GCL; thick } \\
\text { INL }\end{array}$ & Normal & - & None (8) \\
\hline \multicolumn{9}{|c|}{ Functional defects in the INL or OPL } \\
\hline dropje & $\operatorname{drp}^{\operatorname{tr256a}}$ & Defective & Defective & Defective & $\begin{array}{c}\text { Normal; possibly late } \\
\text { degeneration }\end{array}$ & No b-wave & Normal & None $(5,8)$ \\
\hline noir & $\operatorname{nir}^{\mathrm{tp} 89 \mathrm{a}}$ & Defective & Defective & Defective & Normal & No b-wave & Normal & $\begin{array}{l}\text { Locomotor impair- } \\
\text { ment }(4,8)\end{array}$ \\
\hline steifftier & $s t e^{\mathrm{tf} 220 \mathrm{a}}$ & Defective & - & Defective & Normal & ND & Normal & $\begin{array}{l}\text { Locomotor defect } \\
\text { (4) }\end{array}$ \\
\hline \multicolumn{9}{|c|}{ Block of retinotectal impulse propagation/transmission } \\
\hline macho & $\operatorname{mao}^{\mathrm{tt} 261 \mathrm{a}}$ & Defective & Defective & Defective & Normal & Normal & $\begin{array}{l}\text { Enlarged arbors in the } \\
\text { tectum (13) }\end{array}$ & $\begin{array}{l}\text { General sensory } \\
\text { defect (4) }\end{array}$ \\
\hline blumenkohl & blu $^{\text {tc257 }}$ & Defective & Defective & Defective & Normal & Normal & $\begin{array}{l}\text { Enlarged arbors in the } \\
\text { tectum (13) }\end{array}$ & None \\
\hline
\end{tabular}

VBA, Visual background adaptation; ND, not determined; -, not testable.

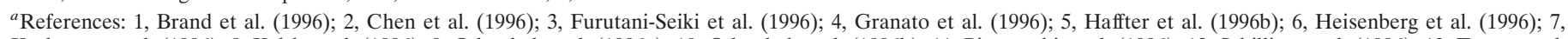

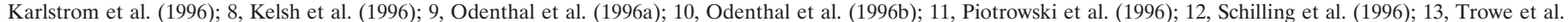
(1996); 14, Whitfield et al. (1996).

stimuli, despite a severely disturbed retinotectal map (Trowe et al., 1996). Among the pathfinding mutants, astray probably displays the most dramatic defect discovered so far: RGC axons innervate multiple abnormal targets throughout the brain, and few axons reach their correct destination, the contralateral tectum (Karlstrom et al., 1996). Nevertheless, the OKR and the OMR in astray mutants are unaffected.

Mutations at the loci sleepy and grumpy lead to misplaced retinotectal projections (Karlstrom et al., 1996), notochord defects, and an abnormally shaped and folded brain. In the brain, the axon scaffold is present but contains fewer axons than normal, with many axons remaining defasciculated (Schier et al., 1996). Both grumpy and sleepy are irresponsive in our behavioral tests, whereas bashful, which shows severe pathfinding errors similar to grumpy and sleepy, is normal. Histological analysis of the grumpy mutant shows that axonal pathfinding is defective already within the retina (Fig. 5D). Also, the lens does not form properly (Fig.
$5 D)$. The ERG is normal in grumpy. sleepy mutants have shortened photoreceptor outer segments, in addition to the central pathfinding problems described above. Both mutants will aggregate pigment in response to light exposure, indicating that they are not completely blind. A combination of several defects may contribute to their visual disturbance.

Another mutant trio, boxer, dackel, and pinscher, share a particular pathfinding syndrome in common but are heterogeneous in their behavioral phenotype. In these mutants, axons originating in the dorsal retina grow along both brachia of the optic tract, rather than only along the ventral brachium. Once having entered the tectum from both ends, the misrouted fibers correct their course and project to the proper retinotopic position (Karlstrom et al., 1996; Trowe et al., 1996). All three mutants have jaw defects as well (Van Eeden et al., 1996). These morphological phenotypes are most severe in dackel, intermediate in boxer, and mildest in pinscher. In our tests, dackel and boxer appear to be visually 

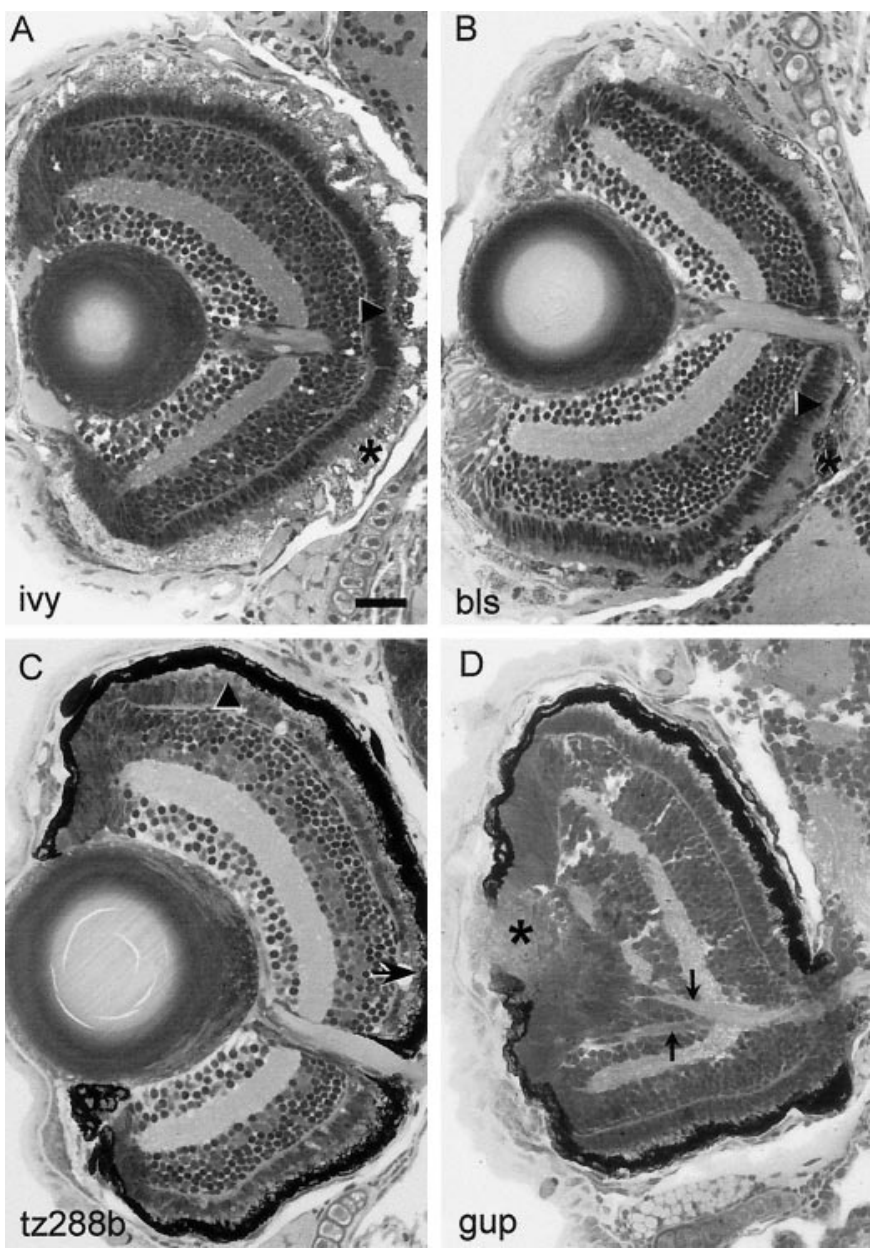

Figure 5. Retinal histology of blind mutants with outer-retina dystrophy $(A-C)$ or developmental defects $(D)$. Compare with wild-type retina in Figure $4 A$. $A$, In ivory (ivy) mutants RPE degeneration is accompanied by PhR loss. $B$, blass (bls) mutants show patchy degeneration of the RPE and the PhRs. $C, t z 288 b$ mutants display PhR degeneration (arrowheads) but no obvious defects in the RPE. In $A-C$, arrows point to degenerated PhR, arrowheads point to $\mathrm{PhR}$ with shortened outer segments, and asterisks indicate abnormal RPE. D, grumpy ( gup) larvae have a misshaped lens (asterisk) with overgrowing RPE. The optic nerve branches abnormally in the retina (arrowheads) and in the CNS (Karlstrom et al., 1996). This mutant is behaviorally blind but shows ERG responses (data not shown). Scale bar, $50 \mu \mathrm{m}$.

normal, whereas pinscher is impaired. The penetrance of the defect in pinscher is $60 \%$ in the OMR and somewhat lower in the OKR. Mutants that are behaviorally irresponsive also fail to aggregate melanin pigment. Motility and ERG are unaffected in pinscher. Its retina is normally layered, although the inner nuclear layer (INL) is expanded, and counts from two animals indicate an increase in INL cell number of $\sim 25 \%$. It is unclear whether and how this morphological change is related to the visual impairment.

blowout represents a special case of a mutant with occasional OKR defect. The OMR, ERG, and background adaptation are all normal, and all retinal layers are present in normal thickness. In some mutants, the eye extends into the brain by forming massive folds (Fig. 6). The most strongly affected individuals are OKRdeficient obviously because of mechanical hindrance of their eye movements.

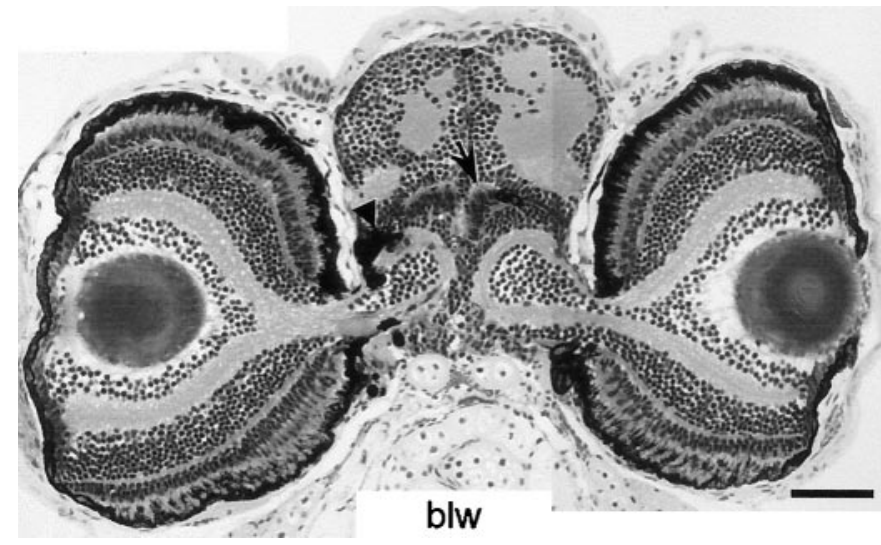

Figure 6. blowout (blw). Transverse sections through the head of a $5 \mathrm{dpf}$ blowout mutant show that the eyes invaginate into the brain but still maintain a normal layering, including RPE (arrowhead) and PhR. This mutant responds properly to optomotor stimuli. Scale bar, $100 \mu \mathrm{m}$.
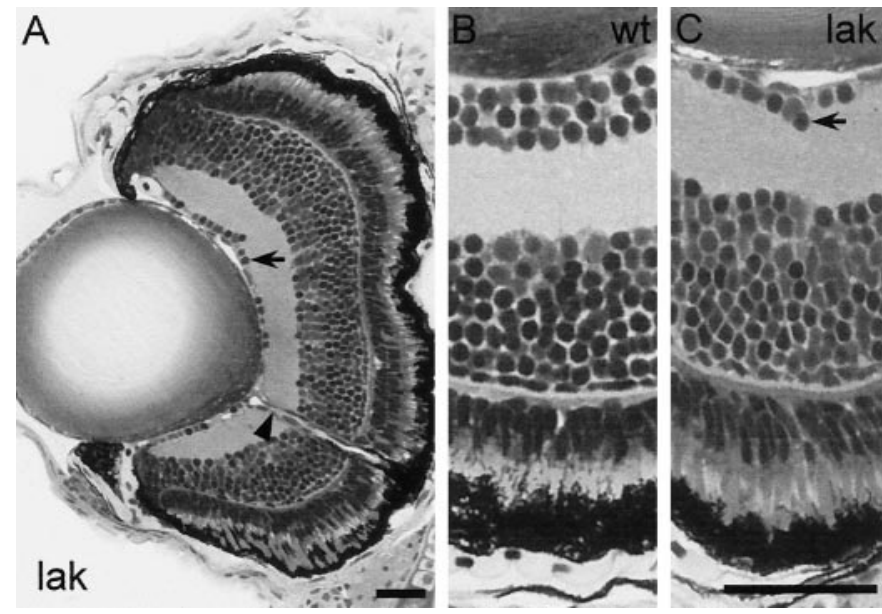

Figure 7. lakritz (lak). A, Transverse sections of a lakritz mutant eye at 5 $\mathrm{dpf}$ reveal the absence of most cells in the GCL. The eye is normal in size and overall morphology. The crumpling of the RPE is a fixation artifact. $B, C$, Higher magnifications of wild-type $(B)$ and lakritz $(C)$. Arrows point to diminished GCL, and the arrowhead points to thin optic nerve. The INL of lakritz is enlarged in proportion to the decrease of the GCL. This mutant is blind in the OMR but shows residual OKR and a normal ERG. Scale bar, $50 \mu \mathrm{m}$.

\section{lakritz mutants fail to generate a large fraction of retinal ganglion cells}

Homozygous lakritz mutants lack an OMR, and only one of eight mutant individuals shows an OKR. The penetrance of the OKR failure varies between clutches. Behavior and external morphology of these mutants are otherwise inconspicuous. Tissue sections reveal that the lakritz retina specifically lacks most of its RGCs. Only $\sim 20 \%$ of cells in the ganglion cell layer (GCL) are spared by the mutation (Fig. 7). Some of these cells may be displaced amacrine cells. The optic nerve is variably reduced (Fig. 7A) or absent, mirroring the variable penetrance of the behavioral problem. Attempts to label RGC axons in the optic nerve by intraocular DiI injection, although successful in all wild-type fish $(n=$ $18)$, failed in the mutants $(n=17)$. This failure can be ascribed to the complete loss of optic axons in most mutants and to the limited labeling efficiency of DiI. We are currently cataloging the RGC types in zebrafish larvae to establish the baseline data necessary to interpret the specificity of the lakritz mutation. 
We have begun to investigate the mechanism of cell loss in lakritz mutants. If, in the wild type, the lakritz gene product acts to determine RGC fate during development, we may expect the number of other cell types in the mutant retina to increase in proportion to the decrease of RGCs. To address this question, we counted the total number of cell profiles in the INL of two mutant individuals and two siblings and found that the number of cells in the INL is increased by approximately the same number that it is decreased in the GCL. This difference is reflected in an increased thickness of the INL (Fig. 7B,C).

The mutation could affect a gene necessary for ganglion cell determination. When mutated, the cells that would normally become RGCs may develop into INL neurons instead, perhaps into amacrine cells. Alternatively, the mutation could act independently at two places, both in RGC precursors and in INL neurons, suppressing one and promoting the other. In the latter scenario, the reduced number of RGCs in lakritz could be caused by a failure to generate these cells or by cell death or degeneration. At three developmental stages tested (4.5, 7, and $12 \mathrm{dpf}$ ), the absolute number of RGCs was unchanged, suggesting that the cell population is stable once the GCL has formed. Although we cannot exclude the possibility that RGCs are eliminated by cell death before $4.5 \mathrm{dpf}$, our observations are consistent with the hypothesis that RGCs are never being generated in lakritz.

\section{Reversed OKR in belladonna correlates with misrouting of crossing axons}

belladonna mutant larvae frequently display a peculiar reversal of the direction of eye movements in the OKR, which is never observed in wild type. Their eyes move in episodes of smooth pursuits, interrupted by fast resets, similar to wild type, but the direction of eye movement is opposite to the drift direction of the optical stimulus. Thus, a clockwise rotation evokes a counterclockwise tracking movement of the eye and vice versa. Among 421 belladonna mutant animals tested, 266 (63\%) showed normal responses for both eyes, 147 (35\%) showed reversed OKR for both eyes, and $8(2 \%)$ showed reversed OKR for one eye and normal OKR for the other. The OMR of belladonna occurs in the proper direction.

In belladonna mutants, a variable fraction of RGC axons aberrantly project to the ipsilateral tectum (Karlstrom et al., 1996), as revealed by injection of DiI into one eye. To ask whether the misrouting phenotype was correlated with the OKR defect, we measured the OKR for 284 individual eyes. One hundred fifty-two showed normal OKR, and 132 showed reversed OKR. We then fixed the fish and injected their eyes with DiI. In $44 \%$ of 284 belladonna eyes injected with DiI, axons projected correctly to the contralateral tectum, $41 \%$ projected exclusively to the ipsilateral tectum, and $15 \%$ reached both tecta. Of the eyes with normal OKR, $82 \%$ projected exclusively and $18 \%$ projected predominantly to the contralateral tectum. Of the eyes with reversed OKR, $89 \%$ projected exclusively and $11 \%$ projected predominantly to the ipsilateral tectum. Not a single case was found in which an ipsilaterally projecting eye responded normally or a contralaterally projecting eye responded with an opposite sign. This strong correlation suggests that the misrouting of retinal projections in belladonna alters its optokinetic behavior and is consistent with the phenotype of adult goldfish with experimentally induced ipsilateral projections (see Discussion).

\section{Mutations of noir and dropje, as well as macho and blumenkohl, cause disruptions of signal transmission in the retina and beyond}

Among the mutants with failure of OKR and OMR, noir and dropje have reduced or altered ERG b-waves, indicating deficits either at the stage of transmission from photoreceptors to bipolars in the OPL or in processing by interneurons of the INL (Fig. $3 B$; ERG of noir). The ERG a-wave (generated by photoreceptor currents) and the histology of the retina appear unaffected. The dropje retina generally degenerates at later stages (data not shown). noir is late-larval lethal ( $14 \mathrm{dpf})$, possibly because of starvation, and dropje is adult semiviable. A third locus, steifftier, also displays normal histology, dies at $\sim 8-10 \mathrm{dpf}$, and is behaviorally blind. steifftier mutants have not been available for ERG measurements. We assume that noir and dropje, and possibly steifftier, primarily affect physiological processes within the OPL or the INL of the retina.

In two mutants, macho and blumenkohl, the terminals of retinotectal axons arborize over a wider area compared with wild type (Trowe et al., 1996). blumenkohl has no other obvious phenotype, whereas macho is insensitive to touch (Granato et al., 1996). Both mutants are blind but display normal retinal histologies and normal ERGs. Because expansion of terminal arbors in the adult goldfish tectum has been observed as a consequence of blocking impulse activity (Meyer, 1983; Schmidt and Edwards, 1983) or synaptic transmission in the target area (Schmidt and Buzzard, 1990), this arbor phenotype and the loss of vision could have a common cause in disruption of retinotectal activity.

\section{DISCUSSION}

\section{Behavioral assays reveal visual system-specific defects in zebrafish mutants}

Two behavioral assays were used to investigate the visual abilities of 450 zebrafish mutants previously isolated in a large-scale screen. The assortment available to us consisted of mutants with disruptions of proper tissue patterning, organ formation, and pigmentation, as well as locomotion and the retinotectal projection (Haffter et al., 1996a). By intention, our screen was not biased toward or against certain classes of phenotypes.

Our assays require the fish larvae to move their eyes (OKR) or to actively swim (OMR) to pursue a large moving grating. Both assays test overlapping but not identical features of visual function. The optokinetic assay can, in principle, test a broader range of developmental phenotypes, because immotile mutants not testable with the optomotor assay may still be capable of moving their eyes. Consequently, 261 loci could be tested for OKR, and only 197 loci could be tested for OMR. Furthermore, optokinetic behavior is fully mature $2 \mathrm{~d}$ earlier (4 dpf) than optomotor behavior (6 dpf) and can therefore be tested with younger larvae. To conclude, the optokinetic assay is less selective and more comprehensive than the optomotor assay. The optomotor assay, on the other hand, is more rapid because it measures population responses. The results of both assays are complementary.

Of the 261 testable loci, some of them being represented by more than one allele, $>60$ display conspicuous abnormalities in at least one of our assays (Table 1). More than 40 mutants showed defects in the motor apparatus, early-onset brain degeneration, or disturbance of early brain patterning remotely upstream of visual behavior (Table 2) and were not considered further. Thirteen mutants showed retinal degeneration (Table 3). Twelve mutations produced more specific defects along the visual pathway (Table 4). 


\section{Zebrafish outer-retina dystrophy mutants may serve as models for human diseases}

More than half of the visual disorders identified by us, 13 loci in total, involve retinal degeneration (RD), caused by PhRs or the RPE. As shown in spontaneous rodent mutants with retinal dystrophy and in tissue culture, RPE and PhRs are metabolically and trophically dependent on each other (Tombran-Tink et al., 1995; Sheedlo and Turner, 1996; Hackett et al., 1998; Tsacopoulos et al., 1998) (for review of the older literature, see Bok, 1993). $\mathrm{PhR}$ degeneration in the zebrafish mutants described here could therefore be secondary to the loss of RPE and vice versa. This scenario can be addressed in the future by creating genetic mosaic larvae.

It is noteworthy that, in addition to the 14 loci, there are $\sim 15$ other previously isolated loci that have similar eye pigment phenotypes (Kelsh et al., 1996). Although they fared normally in our behavioral assays, we examined them only as young fish; it is quite possible that, with extended investigation, they may turn out to suffer from RD as well. The two blind mutants identified in previous screens also suffer from degenerative loss of photoreceptors (Brockerhoff et al., 1997; Li and Dowling, 1997). Approximately 100 different types of hereditary human diseases involving retinitis pigmentosa, macular degeneration, or other forms of RD are listed in the OMIM catalog of human genetic disorders at http://www3.ncbi.nlm.nih.gov/omim/ (for review, see GregoryEvans and Bhattacharya, 1998; Milam et al., 1998). Many of these diseases are present in the adult and frequently affect heterozygous carriers, similar to the zebrafish mutant identified by $\mathrm{Li}$ and Dowling (1997). In summary, RD turns out to be the most frequent cause of inherited blindness in humans and zebrafish alike.

Genetic pathways could be shared between fish and humans. In fact, some zebrafish phenotypes strikingly resemble the syndromes of human diseases. To give just one example: in the zebrafish mutants $t p 49 d$ and $t z 288 b$, we find a combination of retinal dystrophy and renal dysplasia, which are the diagnostic features of the human Senior-Loken syndrome (OMIM *266900). In humans, the functions of RD genes fall into the three broad categories: (1) phototransduction, (2) PhR structure, and (3) PhR-RPE metabolism (Gregory-Evans and Bhattacharya, 1998). Work is under way to test for the linkage of zebrafish mutations to zebrafish homologs of human genes. We expect that zebrafish mutants will lend themselves as models to clinical studies on RD.

\section{Visual defects in a zebrafish albino}

Zebrafish lacking melanin in the RPE because of mutation of the sandy locus are blind at larval ages and are visually impaired as adults. Four other zebrafish loci involved in melanin production (golden, mustard, brass, and albino) have normal vision, as far as tested. The sandy eye, including retina and lens, looks normal and seems to function properly, as judged by the presence of a normal or even exaggerated ERG. The latter finding excludes excessive light damage to photoreceptors as being the cause of visual malfunction. The amount of stray light entering the sandy retina is certainly elevated because of absence of absorbing pigment. However, based on our psychophysical and optical experiments, it is unlikely that this effect abolishes pattern vision altogether.

In mammals, melanin deficiency is often linked to visual problems. The retina of albino mammals shows several developmental abnomalities: (1) a disproportiante decussation of crossing retinal axons (Lund, 1965; Cooper and Pettigrew, 1979; Balkema and
Dräger, 1991; Rice et al., 1995; Jeffery, 1997), resulting in a larger fraction of contralaterally projecting RGCs; (2) a lacking fovea (Elschnig, 1913; Stone et al., 1978); and/or (3) a deficit of rod photoreceptors (Jeffery et al., 1994). These retinal defects cannot occur in zebrafish because (1) all axons project to the contralateral tectum, (2) zebrafish do not possess a prominent fovea (although they do show a thickening in the temporal retina), and (3) rods do not contribute to visual responses at the larval ages tested. The visual problem in sandy cannot be caused by any of the developmental deficits typical for albino mammals (Dräger and Balkema, 1987; Jeffery, 1997).

In humans, tyrosinase-deficient albinism is associated with visual problems, such as abnormal nystagmus and reduced acuity, which have been ascribed to the abnormal decussation of RGC axons and to the absence of a fovea, respectively. Strikingly, photophobia, another behavioral manifestation of human albinism, is also observed in adult sandy zebrafish. Application of 3,4-dihydroxy-L-phenylalanine, the precursor of melanin and preferred substrate of tyrosinase, cannot rescue the sandy phenotype (Haffter et al. (1996b). The sandy gene product might therefore be tyrosinase, and the sandy phenotype may be a new model of the human tyrosinase-deficient (or type I) form of oculocutaneous albinism (OMIM *203100).

\section{Retinal ganglion cells are eliminated by the lakritz mutation}

The lakritz mutation completely eliminates the OMR and only in a minority of mutants leaves a residual OKR. These behavioral deficits can clearly be accounted for by a reduced number of RGCs. Only $20 \%$ of the cells in the GCL are spared by the mutation, some of which may be displaced amacrine cells. Because cells in the GCL rarely have axons in lakritz, it has not been possible so far, for technical reasons inherent to the DiI labeling technique, to determine where the remaining RGCs project to. This would be interesting to know in light of an older finding that OMR and OKR are mediated by anatomically separate pathways (Springer et al., 1977).

There are at least three developmental mechanisms that could lead to the absence of RGCs in the mutant: (1) failure to generate these cells, (2) early degeneration of these cells, and (3) transdetermination into a different cell type. At present, we favor the third, because we did not observe indications of cell death in the mutant retina, but rather we found a proportional increase of cells in the INL. We cannot exclude, however, the alternative explanation that the mutation acts in opposite ways at two different sites, decreasing cell number in the GCL, and increasing it in the INL.

The lakritz phenotype most closely resembles the phenotype of the Brn-3b (Brn-3.2) knock-out mouse, which lacks two-thirds of its RGCs (Erkman et al., 1996; Gan et al., 1996). Our preliminary results from genetic linkage analysis, however, suggest that lakritz is not linked to the zebrafish Brn-3b gene (T. Roeser, A. H. Kahn, P. Haffter, R. Geisler, and H. Baier, unpublished observations) and may represent a novel gene.

\section{Ipsilateral projections in belladonna lead to reversed OKR}

Mutations of the belladonna locus lead to misrouting of retinotectal projections to the ipsilateral tectum and to a striking behavioral abnormality: mutant eyes, exclusively or predominantly connected to the ipsilateral side, pursue the drifting grating in a tracking movement that is opposite to the actual stimulus direc- 
tion. This altered behavior is predicted by earlier experiments, which have shown that experimentally induced ipsilateral projections in adult goldfish likewise lead to a reversed OKR (Easter and Schmidt, 1977). Reversed optokinetic nystagmus of genetic origin has also been reported for a congenital human pathology (Halmagyi et al., 1980).

We suggest the following interpretation for the reversed OKR. The retina encodes the motion of the stimulus as either nasal to temporal or temporal to nasal and, in wild type, feeds the information about the direction and velocity to the contralateral visual nucleus that mediates the OKR. The OKR nucleus, in turn, feeds into motor nuclei, which command the eye muscles to turn the eye in register with the stimulus. Both eyes are coupled, so they tend to move conjugately (Easter, 1971), even in cases when only one eye is stimulated. For a stimulus that rotates around the animal (as used here), the sign of the direction will be opposite for the two different eyes, temporal to nasal for one and nasal to temporal for the other. In belladonna, the information about the stimulus is not being fed back to the eye that is receiving it, but it is rather forwarded (primarily) to the eye on the opposite side. This way, the individual eyes reciprocally steer each other's movement: a nasal-to-temporal motion apparently leads to a temporal-tonasal tracking of the eye and vice versa. In the optomotor assay, which does not use rotary stimuli, the direction of motion that the fish see is of the same sign for both eyes. Information crossing from one eye to the other, therefore, does not alter the behavior. Consequently, optomotor behavior of belladonna mutants is normal.

We expect to find that fish with this abnormal circuit are locked into a regenerative feedback loop once they move their eyes in response to the moving stripes, because their reflexive eye movements only aggravate the movement of the retinal image (which the OKR in wild type will compensate). Adult goldfish with surgically induced ipsilateral projections and one eye removed are seen to turn continually in "circus movements" (Easter and Schmidt, 1977). Although such a severe effect has not been observed with belladonna larvae, juvenile and adult belladonna homozygotes have been reported to move in circles (Karlstrom et al., 1996). The belladonna mutant provides a glimpse of the power that genetics may have in the future to dissect circuitry that underlies behavioral programs.

\section{Axon arbor pruning, the hallmark of activity-dependent processes, is disrupted in macho and blumenkohl}

The macho and blumenkohl mutations were originally discovered based on a relatively subtle retinotectal phenotype: their RGC terminal arbors are enlarged in the tectal neuropil (Baier et al., 1996; Trowe et al., 1996). We report here that the mutants are also blind, although their ERG responses are unaffected. There are two reasons to suggest that macho encodes a gene product involved in spike propagation along RGC axons. First, terminal enlargement in the tectum can be phenocopied by infusion of drugs that interfere with impulse activity during zebrafish larval stages in the RGCs (L. Gnügge and S. C. F. Neuhauss, unpublished observations), similar to findings in adult regenerating goldfish (Meyer, 1983; Schmidt and Edwards, 1983). Second, a recent patch-clamp study demonstrates that, in macho mutants, spinal Rohon-Beard neurons lack a voltage-sensitive sodium current required for their excitability (Ribera and NüssleinVolhard, 1998). The most parsimonious explanation of these findings is that the macho gene encodes a sodium channel that is shared in common by Rohon-Beard neurons and RGCs. Given the similarity to the macho phenotype, the blumenkohl gene product may be another component of spike propagation or synaptic transmission in the retinotectal system.

\section{Visual functions are not obviously linked to morphological traits}

An important result from our screen is that it is impossible to predict the involvement of a gene in visual function from its associated morphological phenotype. Visual mutants are found scattered across the numerous phenotypic classes described by Haffter et al. (1996a). In several cases, such as the trio boxer, dackel, and pinscher, which share in common a retinotectal fibersorting and tissue patterning phenotype, some members are found to be blind, whereas others are unaffected.

Eye morphology and cell proliferation in the eye also do not seem to be linked to basic visual performance, perhaps indicating that the two traits are controlled by largely nonoverlapping genetic pathways. Both the tiny microps retina and the giant, overproliferating blowout retina are able to process visual information in a proper manner and to initiate behavioral responses. (Very probably because of mechanical problems in moving their eyes, blowout fish occasionally fail in the optokinetic paradigm.) The latter two mutants are examples of the robustness and adaptability of visual connectivity during development.

It is striking that, in most mutants reported here, the alteration or disruption is located to the retina, although our assays did not bias us toward this part of the visual system. Even when abnormalities outside the retina are observed, such as the enlarged axon arbors in macho and blumenkohl, these phenotypes are likely to be caused by mutations in genes expressed by retinal cells (in this case, RGCs). It is possible that our failure to find centrally acting loci is attributable to the preselection of mutants available to this study. Mutations leading to specific CNS alterations may have escaped the original large-scale screen because they are generally not linked to morphological or otherwise visible defects. A systematic genetic dissection of visual CNS function will require another screen of similar dimension but this time targeted not to morphology but to behavior.

\section{REFERENCES}

Baier H, Klostermann S, Trowe T, Karlstrom RO, Nüsslein-Volhard C, Bonhoeffer F (1996) Genetic dissection of the retinotectal projection. Development 123:415-425.

Balkema GW, Dräger UC (1991) Impaired visual thresholds in hypopigmented animals Vis Neurosci 6:577-585.

Balm PH, Groeneveld D (1998) The melanin-concentrating hormone system in fish. Ann NY Acad Sci 839:205-209.

Benzer S (1973) Genetic dissection of behavior. Sci Am 229:24-37.

Bok D (1993) The retinal pigment epithelium: a versatile partner in vision. J Cell Sci [Suppl] 17:189-195.

Brand M, Heisenberg CP, Warga RM, Pelegri F, Karlstrom RO, Beuchle D, Picker A, Jiang YJ, Furutani-Seiki M, van Eeden FJ, Granato M, Haffter P, Hammerschmidt M, Kane DA, Kelsh RN, Mullins MC, Odenthal J, Nüsslein-Volhard C (1996) Mutations affecting development of the midline and general body shape during zebrafish embryogenesis. Development 123:129-142.

Brenner S (1974) The genetics of Caenorhabditis elegans. Genetics 77:71-94.

Brockerhoff SE, Hurley JB, Janssen-Bienhold U, Neuhauss SCF, Driever W, Dowling JE (1995) A behavioral screen for isolating zebrafish mutants with visual system defects. Proc Natl Acad Sci USA 92:10545-10549.

Brockerhoff SE, Hurley JB, Niemi GA, Dowling JE (1997) A new form of inherited red-blindness identified in zebrafish. $\mathrm{J}$ Neurosci $17: 4236-4242$.

Chen JN, Haffter P, Odenthal J, Vogelsang E, Brand M, van Eeden FJ, Furutani-Seiki M, Granato M, Hammerschmidt M, Heisenberg CP, 
Jiang YJ, Kane DA, Kelsh RN, Mullins MC, Nüsslein-Volhard C (1996) Mutations affecting the cardiovascular system and other internal organs in zebrafish. Development 123:293-302.

Clark DT (1981) Visual responses in developing zebrafish. PhD thesis. Eugene, OR: University of Oregon.

Cooper ML, Pettigrew JD (1979) The retinothalamic pathways in Siamese cats. J Comp Neurol 187:313-348.

Dowling J (1987) The retina: an approachable part of the brain. Cambridge, MA: Harvard UP.

Dräger UC, Balkema GW (1987) Does melanin do more than protect from light? Neurosci Res [Suppl] 6:S75-S86.

Driever W, Solnica-Krezel L, Schier AF, Neuhauss SCF, Malicki J, Stemple DL, Stainier DY, Zwartkruis F, Abdelilah S, Rangini Z, Belak J, Boggs C (1996) A genetic screen for mutations affecting embryogenesis in zebrafish. Development 123:37-46.

Easter Jr SS (1971) Spontaneous eye movements in restrained goldfish. Vision Res 11:333-342.

Easter Jr SS, Nicola GN (1996) The development of vision in the zebrafish (Danio rerio). Dev Biol 180:646-663.

Easter Jr SS, Schmidt JT (1977) Reversed visuomotor behavior mediated by induced ipsilateral retinal projections in goldfish. J Neurophysiol 40:1245-1254.

Elschnig A (1913) Zur Anatomie des menschlichen Albino-Auges. Graefes Arch Ophthalmol 84:401-419.

Erkman L, McEvilly RJ, Luo L, Ryan AK, Hooshmand F, O'Connell SM, Keithley EM, Rapaport DH, Ryan AF, Rosenfeld MG (1996) Role of transcription factors Brn-31 and Brn-32 in auditory and visual system development. Nature 381:603-606.

Furutani-Seiki M, Jiang YJ, Brand M, Heisenberg CP, Houart C, Beuchle D, van Eeden FJ, Granato M, Haffter P, Hammerschmidt M, Kane DA, Kelsh RN, Mullins MC, Odenthal J, Nüsslein-Volhard C (1996) Neural degeneration mutants in the zebrafish, Danio rerio. Development 123:229-239.

Gan L, Xiang M, Zhou L, Wagner DS, Klein WH, Nathans J (1996) POU domain factor Brn-3b is required for the development of a large set of retinal ganglion cells. Proc Natl Acad Sci USA 30:3920-3925.

Granato M, van Eeden FJ, Schach U, Trowe T, Brand M, Furutani-Seiki M, Haffter P, Hammerschmidt M, Heisenberg C P, Jiang YJ, Kane DA, Kelsh RN, Mullins MC, Odenthal J, Nüsslein-Volhard C (1996) Genes controlling and mediating locomotion behavior of the zebrafish embryo and larva. Development 123:399-413.

Gregory-Evans K, Bhattacharya SS (1998) Genetic blindness: current concepts in the pathogenesis of human outer retinal dystrophies. Trends Genet 14:103-108.

Hackett SF, Friedman Z, Freund J, Schoenfeld C, Curtis R, DiStefano PS, Campochiaro PA (1998) A splice variant of trkB and brain-derived neurotrophic factor are co-expressed in retinal pigmented epithelial cells and promote differentiated characteristics. Brain Res 789:201-212.

Haffter P, Granato M, Brand M, Mullins MC, Hammerschmidt M, Kane DA, Odenthal J, van Eeden FJ, Jiang YJ, Heisenberg CP, Kelsh RN, Furutani-Seiki M, Vogelsang E, Beuchle D, Schach U, Fabian C, Nüsslein-Volhard C (1996a) The identification of genes with unique and essential functions in the development of the zebrafish, Danio rerio. Development 123:1-36.

Haffter P, Odenthal J, Mullins MC, Lin S, Farrell MJ, Vogelsang E, Haas F, Brand M, Vaneeden FJM, Furutani-Seiki M, Granato M, Hammerschmidt M, Heisenberg CP, Jiang YJ, Kane DA, Kelsh RN, Hopkins N, Nüsslein-Volhard C (1996b) Mutations affecting pigmentation and shape of the adult zebrafish. Dev Genes Evol 206:260-276.

Halmagyi GM, Gresty MA, Leech J (1980) Reversed optokinetic nystagmus $(\mathrm{OKN})$ : mechanism and clinical significance. Ann Neurol 7:429-435.

Heisenberg CP, Brand M, Jiang YJ, Warga RM, Beuchle D, van Eeden FJ, Furutani-Seiki M, Granato M, Haffter P, Hammerschmidt M, Kane DA, Kelsh RN, Mullins MC, Odenthal J, Nüsslein-Volhard C (1996) Genes involved in forebrain development in the zebrafish, Danio rerio. Development 123:191-203.

Jeffery G (1997) The albino retina: an abnormality that provides insight into normal retinal development. Trends Neurosci 20:165-169.

Jeffery G, Darling K, Whitmore A (1994) Melanin and the regulation of mammalian photoreceptor topography. Eur J Neurosci 6:657-667.

Karlstrom RO, Trowe T, Klostermann S, Baier H, Brand M, Crawford AD, Grunewald B, Haffter P, Hoffmann H, Meyer SU, Muller BK, Richter S, van Eeden FJ, Nüsslein-Volhard C, Bonhoeffer F (1996)
Zebrafish mutations affecting retinotectal axon pathfinding. Development 123:427-438.

Kelsh RN, Brand M, Jiang YJ, Heisenberg CP, Lin S, Haffter P, Odenthal J, Mullins MC, van Eeden FJ, Furutani-Seiki M, Granato M, Hammerschmidt M, Kane DA, Warga RM, Beuchle D, Vogelsang L, NüssleinVolhard C (1996) Zebrafish pigmentation mutations and the processes of neural crest development. Development 123:369-389.

Li L, Dowling JE (1997) A dominant form of inherited retinal degeneration caused by a non-photoreceptor cell-specific mutation. Proc Natl Acad Sci USA 94:11645-11650.

Lund RD (1965) Uncrossed visual pathways of hooded and albino rats. Science 149:1506-1507.

Marmor M, Zrenner E (1995) Standard for clinical electroretinography, 1994 update. Doc Ophthalmol 89:199-210.

Meyer RL (1983) Tetrodotoxin inhibits the formation of refined retinotopography in goldfish. Brain Res 282:293-298.

Milam AH, Li ZY, Fariss RN (1998) Histopathology of the human retina in retinitis pigmentosa. Prog Retin Eye Res 17:175-205.

Mullins MC, Hammerschmidt M, Haffter P, Nüsslein-Volhard C (1994) Large-scale mutagenesis in the zebrafish: in search of genes controlling development in a vertebrate. Curr Biol 3:189-202.

Nüsslein-Volhard C, Wieschaus E (1980) Mutations affecting segment number and polarity in Drosophila. Nature 287:795-801.

Odenthal J, Haffter P, Vogelsang E, Brand M, van Eeden FJ, FurutaniSeiki M, Granato M, Hammerschmidt M, Heisenberg CP, Jiang YJ, Kane DA, Kelsh RN, Mullins MC, Warga RM, Allende ML, Weinberg ES, Nüsslein-Volhard C (1996a) Mutations affecting the formation of the notochord in the zebrafish, Danio rerio. Development 123:103-115.

Odenthal J, Rossnagel K, Haffter P, Kelsh RN, Vogelsang E, Brand M, van Eeden FJ, Furutani-Seiki M, Granato M, Hammerschmidt M, Heisenberg CP, Jiang YJ, Kane DA, Mullins MC, Nüsslein-Volhard C (1996b) Mutations affecting xanthophore pigmentation in the zebrafish, Danio rerio. Development 123:391-398.

Piotrowski T, Schilling TF, Brand M, Jiang YJ, Heisenberg CP, Beuchle D, Grandel H, van Eeden FJ, Furutani-Seiki M, Granato M, Haffter P, Hammerschmidt M, Kane DA, Kelsh RN, Mullins MC, Odenthal J, Warga RM, Nüsslein-Volhard C (1996) Jaw and branchial arch mutants in zebrafish II: anterior arches and cartilage differentiation. Development 123:345-356.

Ribera AB, Nüsslein-Volhard C (1998) Zebrafish touch-insensitive mutants reveal an essential role for the developmental regulation of sodium current. J Neurosci 18:9181-9191.

Rice DS, Williams RW, Goldowitz D (1995) Genetic control of retinal projections in inbred strains of albino mice. J Comp Neurol 354:459-469.

Schier AF, Neuhauss SCF, Harvey M, Malicki J, Solnica-Krezel L, Stainier DY, Zwartkruis F, Abdelilah S, Stemple DL, Rangini Z, Yang H, Driever W (1996) Mutations affecting the development of the embryonic zebrafish brain. Development 123:165-178.

Schilling TF, Piotrowski T, Grandel H, Brand M, Heisenberg CP, Jiang YJ, Beuchle D, Hammerschmidt M, Kane DA, Mullins MC, van Eeden FJ, Kelsh RN, Furutani-Seiki M, Granato M, Haffter P, Odenthal J, Warga RM, Trowe T, Nüsslein-Volhard C (1996) Jaw and branchial arch mutants in zebrafish I: branchial arches. Development 123:329-344.

Schmidt JT, Buzzard M (1990) Activity-driven sharpening of the regenerating retinotectal projection: effects of blocking or synchronizing activity on the morphology of individual regenerating arbors. J Neurobiol 21:900-917.

Schmidt JT, Edwards DL (1983) Activity sharpens the map during the regeneration of the retinotectal projection in goldfish. Brain Res 269:29-39.

Seeliger M, Neuhauss SCF, Kohler K, Zrenner E (1998) Ganzfeld electroretinography in the zebrafish (Danio rerio). Invest Ophthalmol Vis Sci 39:S975.

Sheedlo HJ, Turner JE (1996) Influence of a retinal pigment epithelial cell factor(s) on rat retinal progenitor cells. Brain Res Dev Brain Res 93:88-99.

Springer AD, Easter Jr SS, Agranoff BW (1977) The role of the optic tectum in various visually mediated behaviors of goldfish. Brain Res 128:393-404.

Stone J, Rowe MH, Campion JE (1978) Retinal abnormalities in the Siamese cat. J Comp Neurol 180:773-782.

Streisinger G, Walker C, Dower N, Knauber D, Singer F (1981) Produc- 
tion of clones of homozygous diploid zebra fish (Brachydanio rerio). Nature 291:293-296.

Tombran-Tink J, Shivaram SM, Chader GJ, Johnson LV, Bok D (1995) Expression, secretion, and age-related downregulation of pigment epithelium-derived factor, a serpin with neurotrophic activity. J Neurosci 15:4992-5003.

Trowe T, Klostermann S, Baier H, Granato M, Crawford AD, Grunewald B, Hoffmann H, Karlstrom RO, Meyer SU, Müller B, Richter S, Nüsslein-Volhard C, Bonhoeffer F (1996) Mutations disrupting the ordering and topographic mapping of axons in the retinotectal projection of the zebrafish, Danio rerio. Development 123:439-450.

Tsacopoulos M, Poitry-Yamate CL, MacLeish PR, Poitry S (1998) Traf- ficking of molecules and metabolic signals in the retina. Prog Retin Eye Res 17:429-442.

van Eeden FJ, Granato M, Schach U, Brand M, Furutani-Seiki M, Haffter P, Hammerschmidt M, Heisenberg CP, Jiang YJ, Kane DA, Kelsh RN, Mullins MC, Odenthal J, Warga RM, Allende ML, Weinberg ES, Nüsslein-Volhard C (1996) Mutations affecting somite formation and patterning in the zebrafish, Danio rerio. Development 123:153-164.

Whitfield TT, Granato M, van Eeden FJ, Schach U, Brand M, FurutaniSeiki M, Haffter P, Hammerschmidt M, Heisenberg CP, Jiang YJ, Kane DA, Kelsh RN, Mullins MC, Odenthal J, Nüsslein-Volhard C (1996) Mutations affecting development of the zebrafish inner ear and lateral line. Development 123:241-254. 